\title{
Developing Mathematics Teaching in Kindergarten
}

\author{
Bat-Sheva Ilany1,2, Miriam Ben-Yehuda1,2 \\ ${ }^{1}$ Beit Berl College, Beit Berl, Israel \\ ${ }^{2}$ Academit Hemdat College, Sdot Negev, Israel \\ Email: bat77i@gmail.com
}

How to cite this paper: Ilany, B. S., \& Ben-Yehuda, M. (2021). Developing Mathematics Teaching in Kindergarten. Creative Education, 12, 369-377.

https://doi.org/10.4236/ce.2021.122026

Received: December 15, 2020

Accepted: February 7, 2021

Published: February 10, 2021

Copyright $\odot 2021$ by author(s) and Scientific Research Publishing Inc. This work is licensed under the Creative Commons Attribution International License (CC BY 4.0).

http://creativecommons.org/licenses/by/4.0/

\begin{abstract}
The emphasis on teaching mathematics in early childhood and the change in the responsibilities of pre-school teachers have emphasized the need for creating new and accommodated tools that can provide teachers with solid foundation and methodical knowledge. This article demonstrates how a well-structured activity database can empower early-childhood teachers to engage children in a wide range of mathematical activities, and give them a sense of competence and self-confidence. The program was tested in 18 kindergartens. The study method was qualitative, employing the following tools: Semi-structured interviews and Observations. As a result, these teachers engage the children in mathematical activities more frequently and are more inclined to attempt a variety of new teaching methods.
\end{abstract}

\section{Keywords}

Mathematics Education, Kindergarten, Thinking Skills, Preschool, Math Activities

\section{Preface}

During the past few years, a call has been issued to intensify, expand and improve pre-science and mathematics curricula for young children and to a transition from a traditional learning environment to a constructivist, active and social learning environment (Cobb, Wood, Yackel, \& McNeal, 1992). In addition, studies conducted in recent years indicate that teachers assigned with teaching mathematics in preschool find themselves facing difficulties and feelings of incapacity for the job. This may, in part, stem from negative personal experiences, but it is also due to lack of appropriate Teacher Training in preschool mathematics (e.g. Ben-Yehuda \& Ilany, 2008; Guo, Justice, Sawyer, \& Tompkins, 2011, Ilany \& Hassidov, in press).

At a young age, according to Piaget, when children begin to be ready for for- 
mal-abstract learning, their thinking patterns are formed and their representational-visual and verbal representation systems are taking shape. The limitations of age lead to reliance on sensory impressions, which cause the child difficulties in generalization, such as conservation and reversibility. Notwithstanding these difficulties, developmental psychology stresses that such change can occur in a physical-social environment that provides opportunities for physical experience with objects, for making assumptions, reasoning and explaining, and for conducting negotiations while employing mathematical language. It is important to provide the child with problems to solve that meet his unique needs. Through these problems the child should be able to discover, apply and bridge between understanding mathematics as an abstract body of knowledge and the relevance of mathematics in everyday life (Pimm, 1987; Vygotsky, 1962; Carpenter et al., 1988). In addition, studies have shown that the volume and quality of math practice during preschool predict a child's success in math in elementary school (Clements \& Sarama, 2006, 2014). Since the teachers of young children bear great responsibility for attaining the above objectives, it is very important to assist them by developing appropriate programs. The design of the database array of activities is based on recognizing these needs.

The database that we created for the teachers intended to help them to construct a work program for developing mathematical thinking for young children, to plan and construct a rich, experiential and authentic mathematical learning environment, which combines creativity, discourse and use of language.

Participating in mathematical discourse has been identified as an essential component of younger learners' understanding and reasoning mathematics. Pre-school children are capable of engaging in sophisticated discourse. It was found that when young learners were given opportunities to explain their thinking, elaborate on concepts, and generate mathematical discourse, they also used high-level mathematical activities (Sfard, 2008).

Establishing a learning environment that welcomes children's involvement and challenging tasks is the key to engaging them in discourse.

The joint activity and mutual engagement should be conducted by the kindergarten teacher who orchestrates the mathematical discourse to her pre-school children to build on their developing knowledge and communication skills as young learners. The classroom environment should include a rich variety of appropriate stimuli and meaningful, useful activities, in which students use to create, explore, and express ideas and should be accommodated to suit the individual needs of every learner (Ghousseini, Lord, \& Cardon, 2016).

The database we created intended to meet these goals (Figure 1).

At the foundation of the database is a search table (Figure 2), a matrix with one coordinate listing basic concepts (size, area and quantity, concept of numbers, geometrical concepts) and development skills (comparison and correspondence, classification, continuum and ordering, conservation), and the second coordinate containing the possibilities of processing the information (visual, audio and motor-sensory perception and memory, and skills related to fine and 


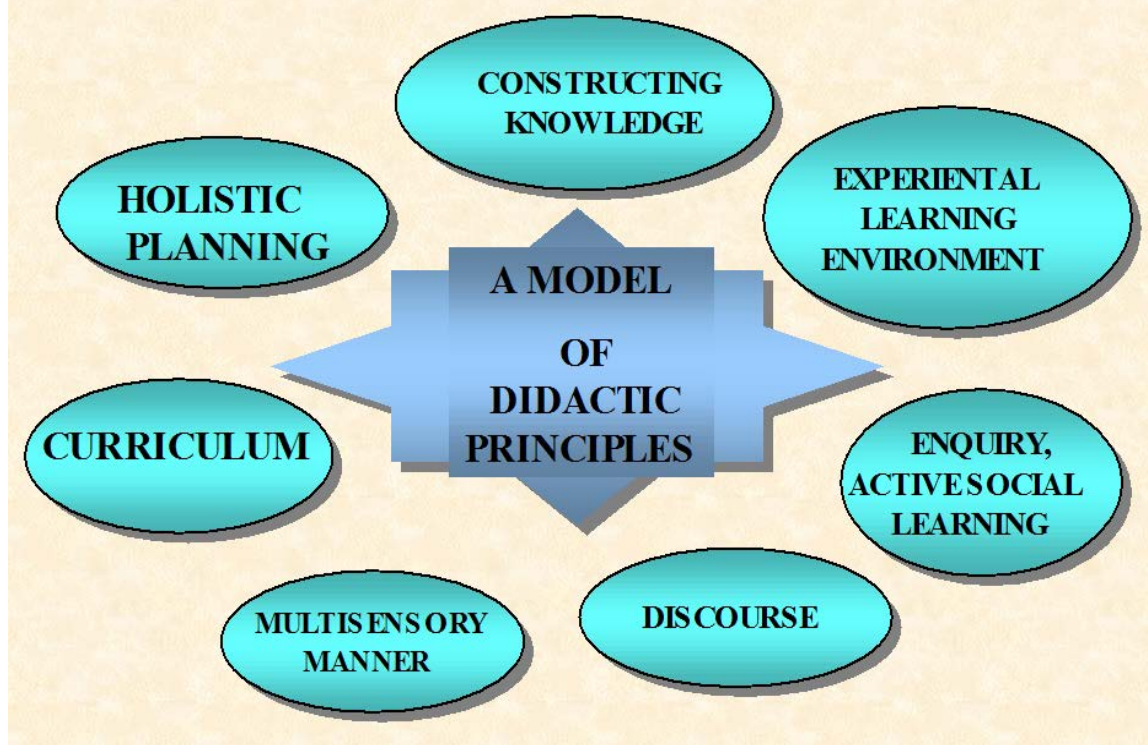

Figure 1. A model of didactic principles of the program.

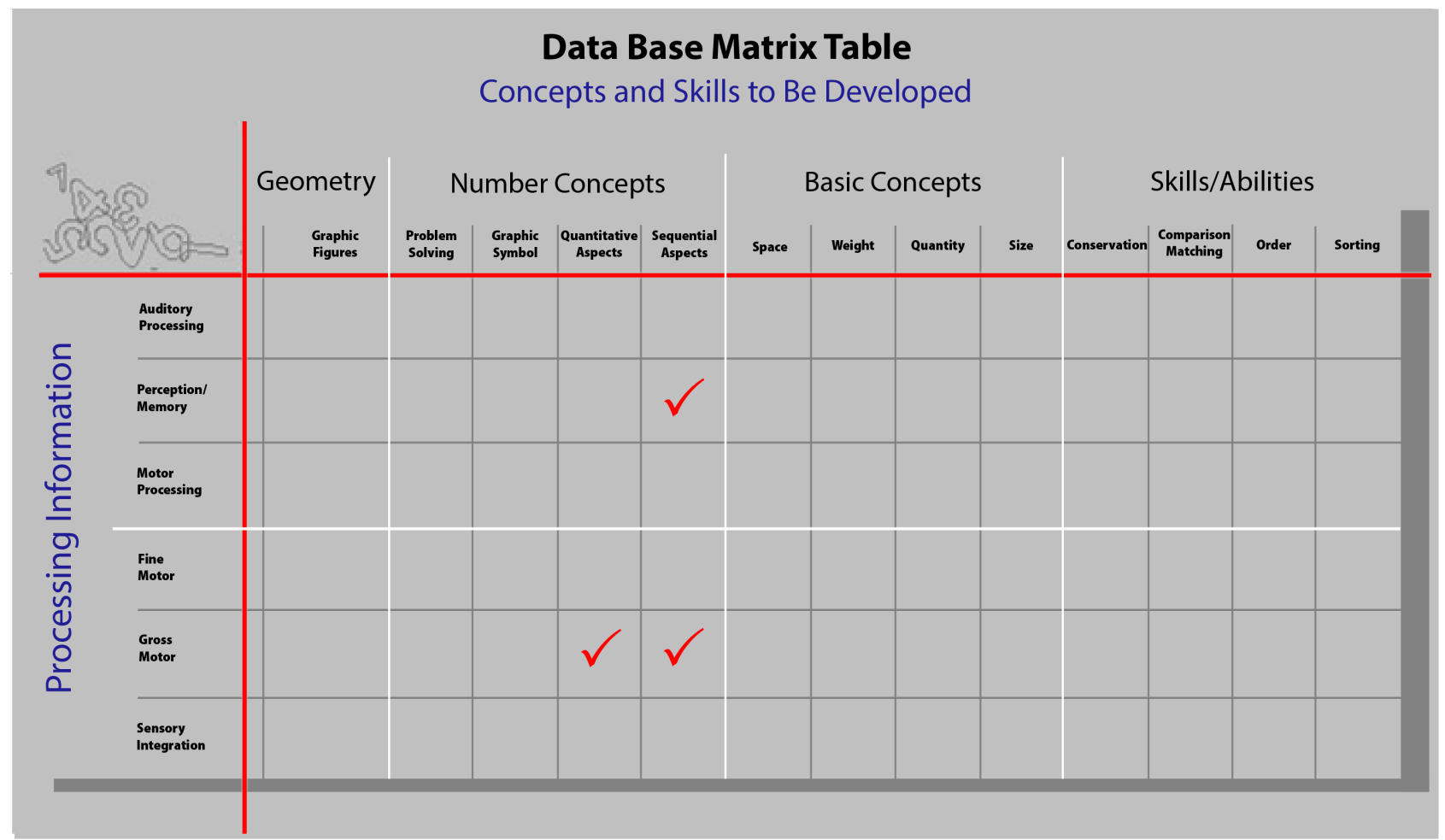

Figure 2. The computerized database, contains a variety of activities for developing the mathematical thinking of young children.

coarse motoric). The intersection of these two coordinates forms a "cell" containing a large number of activities appropriate to the search criteria. Figure 3 is followed with an example of activity. 


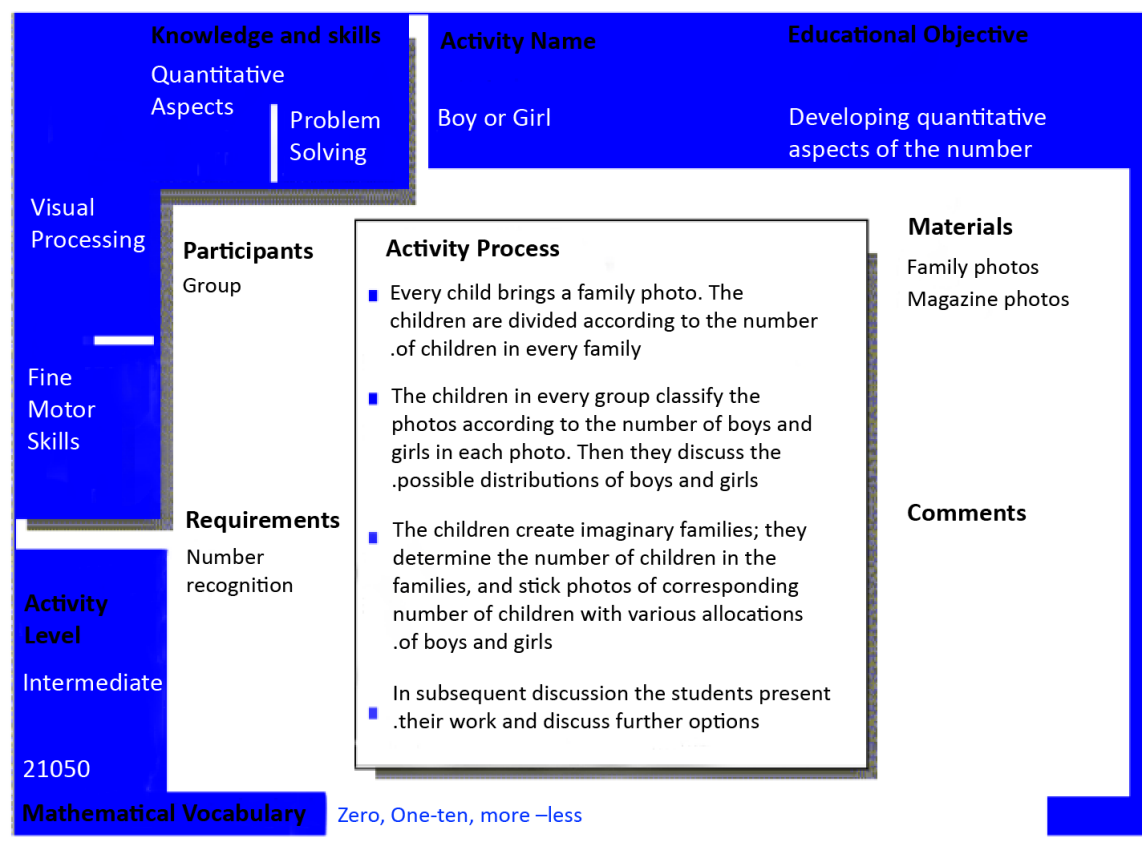

Figure 3. An example of activity: Boy or Girl.

The database contains activity cards describing various ready-to-use activities and organized in each cell in the matrix table according to coordinates. The activity card lists the purpose of the activity, number of participants, activity level and recommended aids. Frequently the activities are accompanied by work sheets that provide activity aids for the user, such as pictures, report forms, card files, playing cards. The accompanying work sheets can be printed in an esthetic and colorful form. The activities are intended for individuals, couples or the entire group and they can be adapted and expanded into study subjects in the kindergarten and classroom and to be flexibly and creatively processed by the teacher.

The database was evaluated in a study carried out in kindergartens (Ben-Yehuda \& Ilany, 2008).

The objectives of this study were:

1) To examine the suitability of the database to the needs of the teacher from the standpoint of content, search criteria and manner of operating the program.

2) To test the effect of the database on the teachers' sense of competence and ways of working.

An example of activity that matches the above search:

In this activity every child brings a family photo and the activity invites the children to engage in high thinking skills as: classifying the photos, comparing the number of boys and girls in each photo and discuss the options. The children also create an imaginary family with various allocations of boys and girls.

The Educational Objective of this activity is to develop quantitative aspects of the number using and problem-solving skills.

Another activity that aims to develop different aspects of the number is demonstrated in the next example: Counting and Preforming (Figure 4). 

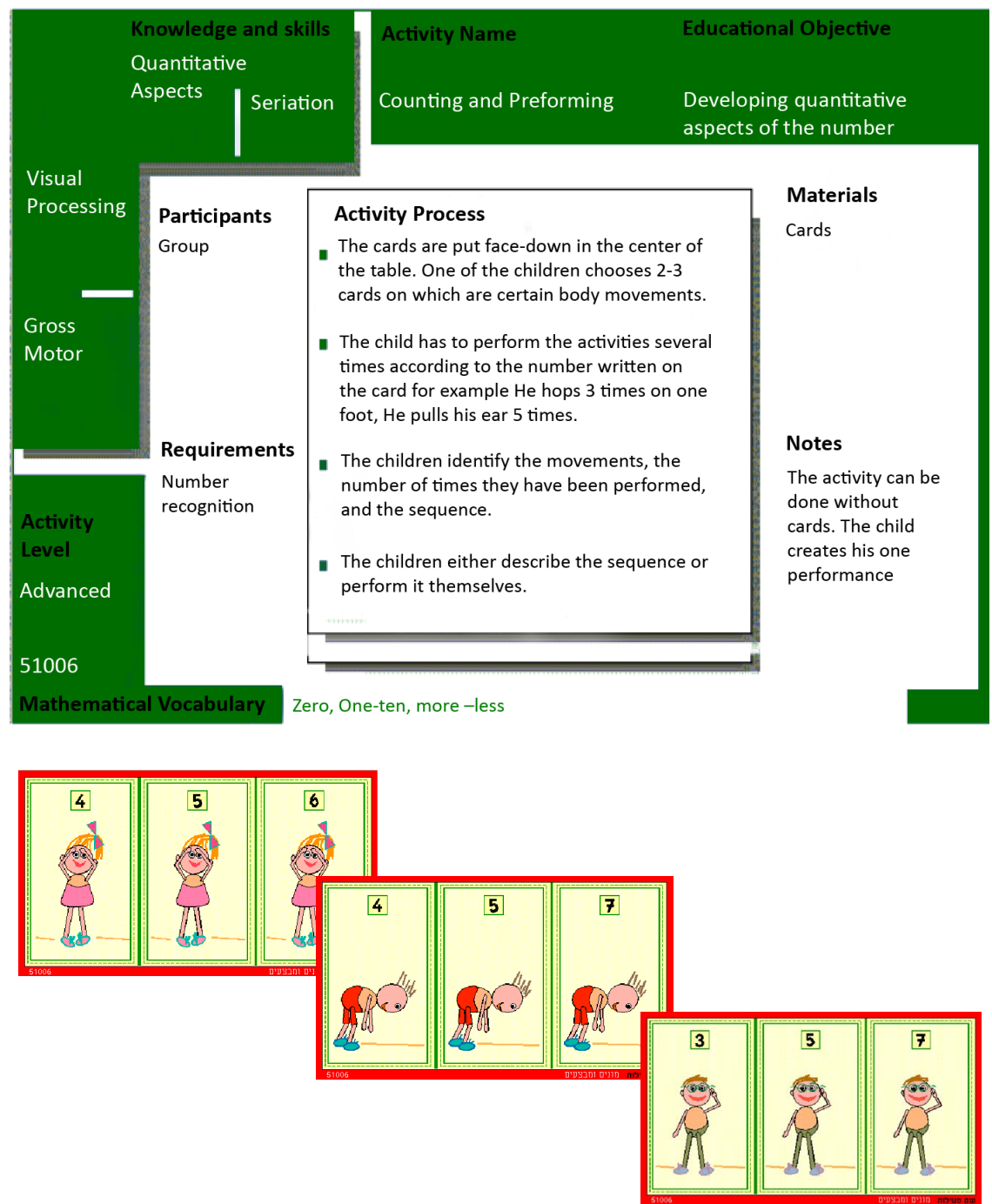

Figure 4. Activity: Counting and Preforming.

This activity is especially suitable for those children who need a multiple sensory experience meaning to sense the quantitative meaning of a number. It is important to accompany the activity with discourse and verbalization of the processes they are engaged in. The kindergarten teacher should guide the children to have a mathematical discourse by posing directed questions such as: how many movements did you perform? How many jumps did you perform more than ear pull? That way they will understand the quantitative meaning of the number and also the order of the number in the series of numbers. In addition, it is possible to encourage the children to record their activity with the aid of a variety of techniques: orally, drawings, pasting or with the aid of other demonstrations.

Recording the activities by the kindergarten teacher can be a means to observe and monitor the development of the individual and the group.

\section{Research Method}

The study was conducted over a two-year period with 18 teachers. The teacher 
population was heterogeneous, from various sectors and regions. Half were new teachers with up to five years teaching experience and the rest had 6 - 20 years of teaching experience.

The study method was qualitative, employing the following tools:

Semi-structured interviews: Each of the teachers was interviewed four times. Each interview lasted about 90 minutes. The first interview was conducted in the beginning of the first year. Its purpose was to determine the manner in which the teachers worked her approach and the frequency with which they worked in mathematics. The second interview was conducted about a month after starting the program, the third interview took place close to the end of the first year and the fourth interview was conducted in the end of the second year. The purpose of the second and third interviews was to study the operation of the database and its contribution to teaching mathematics to young children. The objective of the fourth interview was to obtain feedback from teachers who were using the computerized database for the second year, in order to further validate the findings.

Observations: Observation sessions were conducted once in 9 of the 17 kindergartens (one in each kindergarten). The observations were prearranged and lasted about an hour. The purpose of the observations was to validate the findings that emerged in the interviews. A conversation, in the form of an interview was held at the end of each observation session, and included questions about the activities that had taken place.

\section{Findings}

The study findings indicate that following the use of the database, changes took place in two principal areas:

1) Changes in the teacher's sense of competence and degree of confidence and readiness to deal with the subject of arithmetic and with the development of mathematical thinking in young children. The change is expressed in the sense of self-confidence acquired by the teacher when exposed to organized activities in a structured and gradual manner. The reservations regarding the teaching of arithmetic that were mentioned by many kindergarten teachers at the outset of the project were replaced by a feeling of readiness which was expressed by a higher frequency of engaging the children in arithmetic-related subjects. According to the teachers: "I hated arithmetic, this database was the only thing that led me to deal with arithmetic... I crossed the barrier." "Everything became simpler, more available and non-threatening. The arithmetic corner changed form, leading me to engage more in arithmetic."

2) Changes in the teachers' teaching methods came along with the developing sense of competence and acquired self-confidence:

The teachers commented on the structured nature of the database, which enabled them to view the knowledge accumulated over the years of their work in an organized and methodical manner. The matrix was cited as an important factor in structuring the teacher's activity, organizing knowledge and under- 
standing the unique contribution of every activity. " $P$ ve been a kindergarten teacher for 20 years and $1 \mathrm{~m}$ familiar with many things, but the organization and order help me be more focused. Defining the objective is very helpful because although I acted in the past, I did not always think of the objective." Another kindergarten teacher: "We, the kindergarten teachers, know how to do, but the contribution underlying every activity is not always clear to us. The activity cards make it possible for us to better understand the concepts... when you know why, the 'how' comes out better as well."

Using the database led to self-monitoring and control by teachers of their teaching process. The teachers used the matrix as both a reporting table following the activities that they carried out, and indicate which activities were still needed in the future. On the general level as well as on the individual level for each child: "By entering the subjects in the matrix, I know what I did and what I need to do."

The varied search options performed via the matrix enabled the teachers to focus on the students' unique needs. "Since the children come from different kindergartens and different levels, I used the database to produce individual activities in order to cope with the existing differences between the children."

Searching the matrix enabled the teachers to vary the work options in the kindergarten and the teacher's attention has been attuned to the "arithmetical" content contained in the various class activities. In other words, the everyday activities in the kindergarten were also used to develop mathematical thinking. Moreover, a number of teachers reported that they were not aware of the possibilities of integrating the teaching of arithmetic with other subjects. For example, it never occurred to most teachers to integrate arithmetic with movement, and they were happy to adopt such ideas in activities with the children: "...Before that, I never thought of arithmetic activities with movement, such a combination would not have accrued to me, arithmetic and movement-this is an innovation for me."

The concepts that need to be taught in the course of activity are noted on the activity cards. This reference helps the teacher to verbalize mathematical concepts: "The clear phrasing helped me to know how to phrase and conceptualize... By using the database, I improved my own capability and thereby the capability of the children in everything pertaining to verbalization of mathematical concepts."

\section{Summary and Conclusion}

Studies have shown (e.g. Hassidov \& Ilany, 2018) that presenting content in a structured form and through models, increases teachers' confidence and makes them more willing to teach math for young children. Findings of the current study indicate that the use of databases for presenting content meets these criteria: the database is structured and well organized thus imparting a sense of confidence and faith and contributing to teachers' willingness to take initiatives and 
risks by striking out into new, unfamiliar areas. Moreover, the table matrix enables accessibility to a wide range of activities that suit different individual needs and permits convenient operation without feeling threatened. It gives teachers a sense of competency and the belief that they can cope with teaching any subject. It is important to note that even teachers who declared that they lacked enthusiasm for teaching math due to previous unsuccessful experiences both as students and as teachers, have changed their minds after using the database.

The emphasis on teaching mathematics in early childhood and the change in the responsibilities of the pre-school teachers (National Scientific Council on Developing Child, 2007) have emphasized the need for creating new and accommodated tools that can provide teachers with solid foundation and methodical knowledge. The tools and knowledge will empower teachers and give them a sense of competence and self-confidence to teach math to young children.

The conclusions of this study are that teachers who are offered a tool that presents content in a well-organized and well-defined format feel greater confidence and competence in teaching mathematics. As a result, these teachers engage children in mathematical activities more frequently and are more inclined to employ new teaching methods.

\section{Conflicts of Interest}

The authors declare no conflicts of interest regarding the publication of this paper.

\section{References}

Ben-Yehuda, M., \& Ilany, B. (2008). The Development of Mathematical Thinking in Young Children: Theory, Research and Practice in Training Teachers. Tel Aviv: Machon Mofet Publications. (In Hebrew)

Carpenter, T. P., Fenemma, E., Peterson, P. L., \& Carey, D. A. (1988). Teachers' Pedagogical Content Knowledge of Students' Problem Solving in Elementary Arithmetic. Journal for Research in Mathematics Education, 19, 385-401. https://doi.org/10.2307/749173

Clements, D. H., \& Sarama, J. (2006). The Young Child's Mathematical Mind. Parent \& Child, 10, 30-37.

Clements, D. H., \& Sarama, J. (2014). The Importance of the Early Years. In R. E. Slavin (Ed.), Science, Technology \& Mathematics (STEM) (pp. 5-9). Thousand Oaks, CA: Corwin Press. http://dx.doi.org/10.4135/9781483377544.n2

Cobb, P., Wood, T., Yackel, E. and McNeal, B. (1992). Characteristics of Classroom Mathematics Traditions: An interactional Analysis. American Educational Research Journal, 29, 573-604.

Ghousseini, H. G., Lord, S. S., \& Cardon, A. C. (2016). Classroom Mathematics Discourse in a Kindergarten Classroom. Psychology of Mathematics \& Education of North America, 1321-1324.

Guo, Y., Justice, L. M., Sawyer, B., \& Tompkins, V. (2011). Exploring Factors Related to Preschool Teachers' Self-Efficacy, Teaching and Teacher Education. International Journal of Research and Studies, 27, 961-968. https://doi.org/10.1016/j.tate.2011.03.008 
Hassidov, D., \& Ilany, B. (2018). Collaboration between Mathematics Facilitators and Preschool Teachers during the Innovative "Senso-Math" Preschool Program. Mathematics Teacher Education and Development, 20, 154-167.

Ilany, B., \& Hassidov, D. (in press). Between Natural Language and Mathematical Symbols $(<,>,=)$ : The Comprehension of Preservice and Preschool Teachers' Perspective of "Numbers" and "Quantity". In A. Raslan, \& D. Hassidov (Eds.), Early Childhood Educational Research: Mathematics, Cognition and Teacher Training (16 p). Leiden: Brill Publishers.

National Scientific Council on the Developing Child. (2007). The Science of Early Childhood Development. Cambridge, MA: Center on Developing Child, Harvard University.

Pimm, D. (1987). Speaking Mathematically: Communication in Mathematics Classrooms. New York, NY: Routledge and Kegan Paul.

Sfard, A. (2008). Thinking as Communicating: Human Development, Development of Discourses, and Mathematizing. Cambridge: Cambridge University Press. https://doi.org/10.1017/CBO9780511499944

Vygotsky, L. S. (1962). Thought and Language. Cambridge, MA: MIT Press. https://content.apa.org/doi/10.1037/11193-000 